\title{
Article \\ The Influence of UV Light on Photodegradation of Acetylsalicylic Acid
}

\author{
Monica Daescu ${ }^{1,2}{ }^{\mathbb{D}}$, Miruna Iota ${ }^{1}$, Constantin Serbschi ${ }^{3}$, Alina C. Ion ${ }^{2}$ and Mihaela Baibarac ${ }^{1, *}$ \\ 1 Laboratory of Optical Processes in Nanostructured Materials, National Institute of Materials Physics, \\ Atomistilor Street 405A, POB MG 7, 077125 Bucharest, Romania; monica.daescu@infim.ro (M.D.); \\ miruna.iota@infim.ro (M.I.) \\ 2 Faculty of Applied Chemistry \& Material Science, University Politehnica of Bucharest, Gh. Polizu Street 1-7, \\ 011061 Bucharest, Romania; ac_ion@yahoo.com \\ 3 Bioelectronic SRL, Cercelus St 54, 100028 Ploiesti, Romania; bioelectronic90@yahoo.com \\ * Correspondence: barac@infim.ro; Tel.: +40-21-369-0170
}

Citation: Daescu, M.; Iota, M.; Serbschi, C.; Ion, A.C.; Baibarac, M. The Influence of UV Light on Photodegradation of Acetylsalicylic Acid. Int. J. Mol. Sci. 2021, 22, 4046. https://doi.org/10.3390/ ijms22084046

Academic Editors: Josef Jampilek and Miloš Hricovini

Received: 4 March 2021

Accepted: 12 April 2021

Published: 14 April 2021

Publisher's Note: MDPI stays neutral with regard to jurisdictional claims in published maps and institutional affiliations.

Copyright: () 2021 by the authors. Licensee MDPI, Basel, Switzerland This article is an open access article distributed under the terms and conditions of the Creative Commons Attribution (CC BY) license (https:// creativecommons.org/licenses/by/ $4.0 /)$

\begin{abstract}
Photodegradation of the aqueous solutions of acetylsalicylic acid, in the absence (ASA) and the presence of excipients (ASE), is demonstrated by the photoluminescence (PL). A shift of the PL bands from 342 and $338 \mathrm{~nm}$ to 358 and 361-397 nm for ASA and ASE in solid state and as aqueous solutions was reported. By exposure of the solution of ASA $0.3 \mathrm{M}$ to UV light, a decrease in the PL band intensity was highlighted. This behavior was revealed for ASA in the presence of phosphate buffer (PB) having the $\mathrm{pH}$ equal to $6.4,7$, and 8 or by the interaction with $\mathrm{NaOH} 0.3 \mathrm{M}$. A different behavior was reported in the case of ASE. In the presence of $\mathrm{PB}$, an increase in the intensity of the PL band of ASE simultaneously with a change of the ratio between the intensities of the bands at 361-364 and 394-397 nm was highlighted. The differences between PL spectra of ASA and ASE have their origin in the presence of salicylic acid (SAL). The interaction of ASE with $\mathrm{NaOH}$ induces a shift of the PL band at 405-407 nm. Arguments for the reaction of ASA with $\mathrm{NaOH}$ are shown by Raman scattering and FTIR spectroscopy.
\end{abstract}

Keywords: acetylsalicylic acid; photoluminescence; Raman scattering; IR spectroscopy

\section{Introduction}

Pharmaceutical compounds have been designed to have a specific mode of action, targeting specific organs, metabolic pathways, or receptors to modulate physiological functions, to treat a disease, and to restore the health of the organism [1]. Non-steroidal anti-inflammatory drugs are a class of drugs that are grouped into drugs with analgesic and antipyretic effects, but also into drugs with anti-inflammatory effects, when used in higher doses [2]. Acetylsalicylic acid (ASA), marketed since 1899 as Aspirin, is known for its antiinflammatory, analgesic, antipyretic, and antithrombotic effects. Due to these therapeutic effects, its ability to alleviate several symptoms related to common viral infections has been recognized, thus being part of the category of drugs worth testing in patients with COVID-19 [3]. The therapeutic schema involving the use of aspirin has been reported to induce a decrease of the mortality rate for COVID-19 positive patients [4]. However, ASA was eliminated in the case of children and people at risk of bleeding, such as pregnant women or patients with high cardiovascular risk [3]. The mechanism as anti-thrombotic agent of ASA in the SARS-COV-2 infections was reported by Shih-Chang Tsai et al. [5]. The optimal dose of ASA in the therapeutic scheme for the SARS-COV-2 infections was reported to be of $1500 \mathrm{mg} /$ day [6-8]. Taking into account that in many infectious diseases, including SARS-COV-2 infections, patients present with temperatures above $36{ }^{\circ} \mathrm{C}$, the influence of temperature on the optical properties of ASA are reported in this work. The reactive nature of the acetyl group found in the structure of aspirin suggests that it may also have off-target chemical reactions that may have a biological effect. As ASA enters 
a cell in the body, much of it will be transformed due to the hydrolysis reaction with the aqueous solution, leading to the formation of salicylic acid (SAL). This reaction, but also others, represents a possibility to use high concentrations of SAL in the cell, which interact with cell molecules and thus disrupt their activity [9]. In this context, we note that the pharmaceutical product containing acetylsalicylic acid and excipients (ASE) is administered for systemic sclerosis [10], ovarian cancer [11], dysphagia [12], prevention of myocardial infarction [13], atrial fibrillation [14], hepatocellular carcinoma [15], Candida parapsilosis [16], venous thromboembolism [17], and for its anti-tumor effect [18].

ASA is a compound containing carboxylic and ester functional groups, the latter being highly vulnerable to hydrolysis under various hydrolytic conditions [19]. Stability testing of pharmaceutical products represents an important part in the drug development process because it provides evidence on how the quality of a drug substance varies with time, under the influence of a variety of environmental factors, such as temperature, humidity, and light [20]. Over the decades, many characterization techniques have been used for the detection of ASA, e.g., UV-VIS absorption spectroscopy [21,22], fluorescence [21,23], powder X-ray diffraction (PXRD) [24,25], FTIR spectroscopy [26], FT-Raman spectroscopy [27], X-ray photoelectron spectroscopy (XPS) [28], nuclear magnetic resonance (NMR) spectroscopy [29], high-performance liquid chromatography (HPLC) [30,31], and cyclic voltammetry (CV) [32].

According to reference [33], the degradation process of ASA was studied using liquid chromatography/mass spectrometry (LC/MS), FTIR, and UV spectrophotometric analysis. Another method that highlights the degradation of ASA is electrochemical oxidation, which was validated by ion chromatograph (IC) and gas chromatography-mass spectrometry (GC-MS) [34]. In these cases, the intermediate compounds formed by the process of photocatalytic oxidation or by other mechanisms of ASA degradation, such as hydrolysis, electrophilic addition, electrons transfer, decarboxylation reaction, aromatic ring opening, and radical reaction, have been shown to be more toxic than ASA. In situ monitoring of photodegradation reactions of various drugs has recently been shown to be possible by various optical methods such as UV-VIS absorption spectroscopy and photoluminescence (PL). Arguments for the formation of reaction compounds were often reported by Raman scattering and IR spectroscopy [35-38]. In order to exemplify this progress, the following issues were reported in previous studies by our team [35-38]: (1) the influence of oxygen from air on the photodegradation process of azathioprine in the powder and tablet state, respectively [38]; (2) the influence of the phosphate buffer (PB) solution with $\mathrm{pH}$ equal to 5.4 on photodegradation of folic acid [37]; and (3) the photodegradation induced by the hydrolysis reaction of melatonin [36] and acetaminophen [35]. In all these studies, PL was found to be a faster optical method in highlighting the photodegradation processes of the above drugs in comparison with the UV-VIS spectroscopy $[35,36]$.

For the particular case of ASA, which is marketed as effervescent tablets, known under the commercial name of Bayer Aspirin and Aspirin plus $C$ or as Aspirin hot drink, the knowledge of the behavior of this active compound in aqueous solutions is of interest. Often, the water has a weakly acidic or basic character. Therefore, in this work, new optical evidence concerning the ASA photodegradation in the presence of the PB solutions with the $\mathrm{pH}$ ranging between 6.4 and 8 will be shown. Preliminary results concerning the dependence of PL spectra with the temperature of the aqueous solutions of ASA or ASE will be also reported. Using PL, the ASA photodegradation reaction in the presence of alkaline media will be analyzed, too. The understanding of the chemical mechanism that takes place by the interaction of ASA with alkaline medium will be explained, taking into account the variations induced to the vibrational proprieties of ASA that will be presented by Raman scattering and FTIR spectroscopy.

\section{Results and Discussion}

Figure 1 shows the photoluminescence excitation (PLE) and PL spectra of ASA and ASE in powder state. 


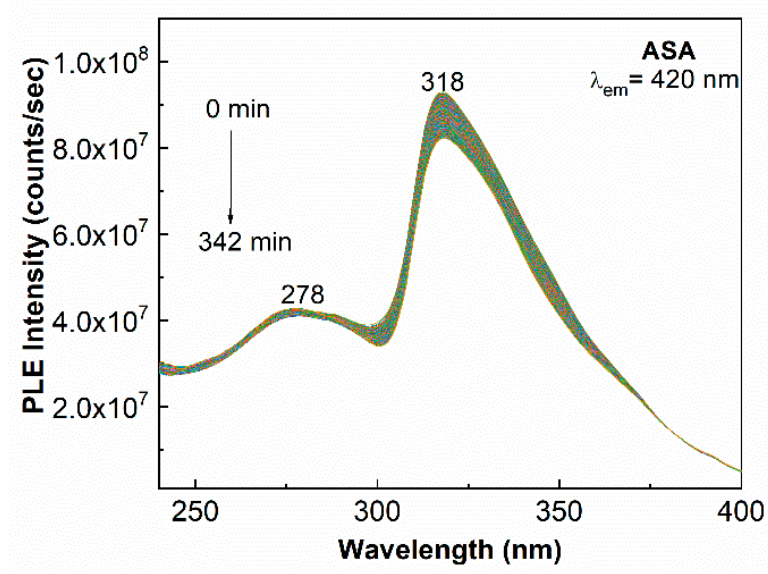

(a)

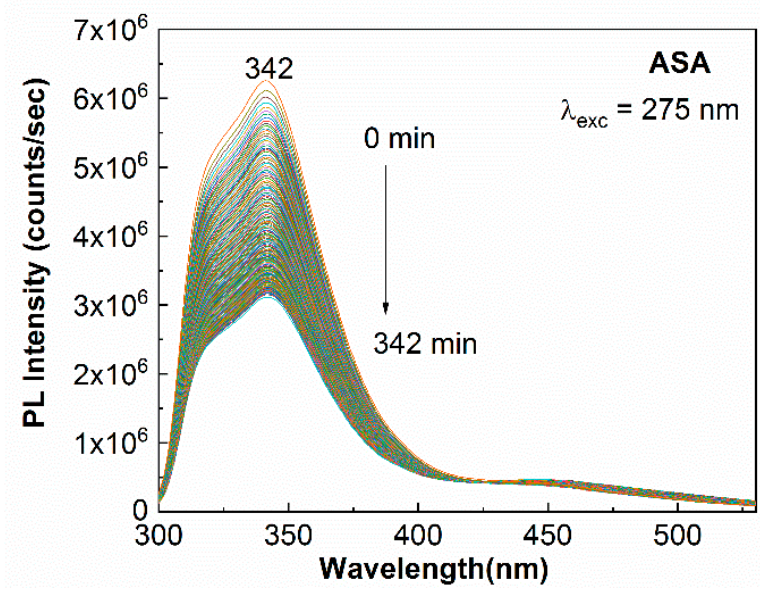

(c)

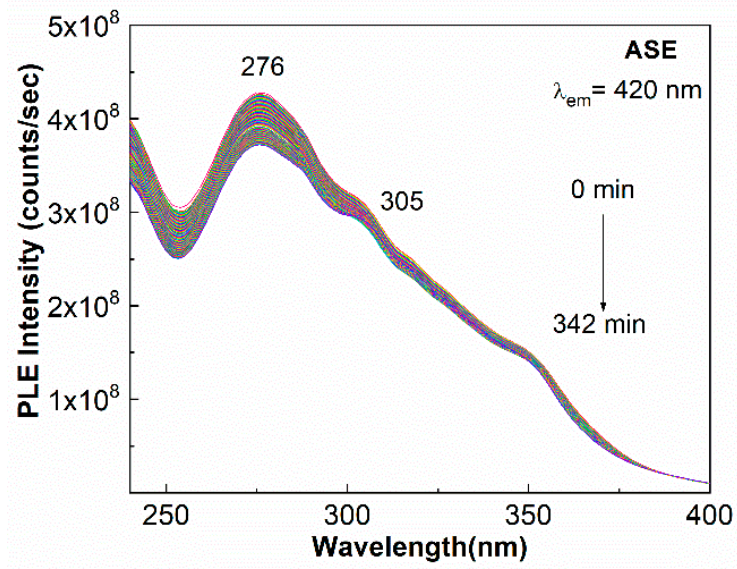

(b)

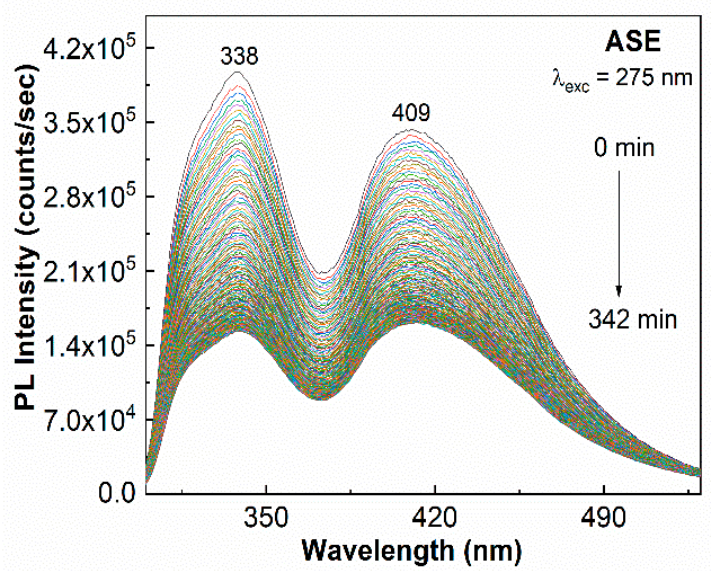

(d)

Figure 1. Photoluminescence excitation (PLE) spectra of ASA (a) and ASE (b), in powder state, recorded at the emission wavelength equal to $420 \mathrm{~nm}$. Photoluminescence (PL) spectra of acetylsalicylic acid (ASA) (c) and pharmaceutical product containing acetylsalicylic acid in the presence of excipients (ASE) (d), in powder state, recorded at the excitation wavelength equal to $275 \mathrm{~nm}$.

The PLE spectrum of ASA is characterized by an intense band with maximum at $318 \mathrm{~nm}$ and another one of low intensity having maximum at $278 \mathrm{~nm}$ (Figure 1a). The ratio between the intensities of the two PLE bands $\left(\mathrm{I}_{318} / \mathrm{I}_{278}\right)$ is equal to 2.17 . The PLE spectrum of ASE shows an intense band with the maximum at $276 \mathrm{~nm}$, having a shoulder at $305 \mathrm{~nm}$. The ratio between the intensities of the two bands $\left(\mathrm{I}_{305} / \mathrm{I}_{276}\right)$ is equal to $\sim 0.72$ (Figure $1 \mathrm{~b}$ ). The exposure of the two samples, i.e., ASA and ASE in powder state, at the UV light, time of $342 \mathrm{~min}$, induced in PLE spectra a change of the $\mathrm{I}_{318} / \mathrm{I}_{278}$ and $\mathrm{I}_{305} / \mathrm{I}_{276}$ ratios at $\sim 1.95$ and $\sim 0.78$, respectively. More important variations were observed in the case of PL spectra of ASA and ASE (Figure 1c,d). Before exposure to UV light, PL spectra were characterized in the case of: (1) ASA by an emission band with a maximum of approx. $342 \mathrm{~nm}$ and (2) ASE through two emission bands with maxima at approx. 338 and $409 \mathrm{~nm}$. These results were in good agreement with those previously published on ASA and salicylic acid (SAL) when PL bands with maxima at $341 \mathrm{~nm}$ and $404 \mathrm{~nm}$, respectively, were reported [21]. The presence of SAL in ASE is a consequence of the partial conversion of ASE into SAL in the presence of water vapors from air adsorbed onto the ASE tablets surface [21]. According to Figure 1c,d, exposure to UV light of the two samples for $342 \mathrm{~min}$ induced, in the case of (1) ASA, a gradual decrease of the PL band intensity with the maximum at $342 \mathrm{~nm}$ from $6.25 \times 10^{6}$ counts/sec to $3.15 \times 10^{6}$ counts/sec and (2) ASE, a progressive decrease in 
the intensity of the PL bands at 338 and $409 \mathrm{~nm}$ from $3.9 \times 10^{5}$ and $3.4 \times 10^{5}$ counts $/ \mathrm{sec}$ to $1.5 \times 10^{5}$ and $1.6 \times 10^{5}$ counts/sec, respectively. The choice of exposure time to UV light took into account the instability of ASA in different biological fluids, for which it was known that the ASA half-life by hydrolysis varies from $0.5 \mathrm{~h}$ to $1.9,16$ or $17 \mathrm{~h}$, when ASA is in human blood, human plasma, human gastric juice, or human duodenal juice, respectively [39]. No additional variations were observed in the PL and PLE spectra after $342 \mathrm{~min}(5.7 \mathrm{~h})$ of exposure of samples to UV light.

In comparison with the powder state, in the case of the aqueous solutions of ASA and ASE, the following differences were noticed before exposure to UV light of the two samples: (1) The PLE and PL spectra of ASA were shifted at $305 \mathrm{~nm}$ and $358 \mathrm{~nm}$, respectively (Figure 2a,b). (2) The PLE spectrum of ASE highlighted two bands with the maxima at $305 \mathrm{~nm}$ and $327 \mathrm{~nm}$ (Figure 2c). The ratio between the intensities of the two bands at $305 \mathrm{~nm}$ ad $327 \mathrm{~nm}\left(\mathrm{I}_{305} / \mathrm{I}_{327}\right)$ became equal to $\sim 0.91$. (3) The PL spectrum of ASE showed an intense band with the maximum at $403 \mathrm{~nm}$ having a shoulder at $358 \mathrm{~nm}$ (Figure 2d). The ratio between the intensities of the two bands at 358 and $403 \mathrm{~nm}\left(\mathrm{I}_{358} / \mathrm{I}_{403}\right)$ was equal to 0.48 .

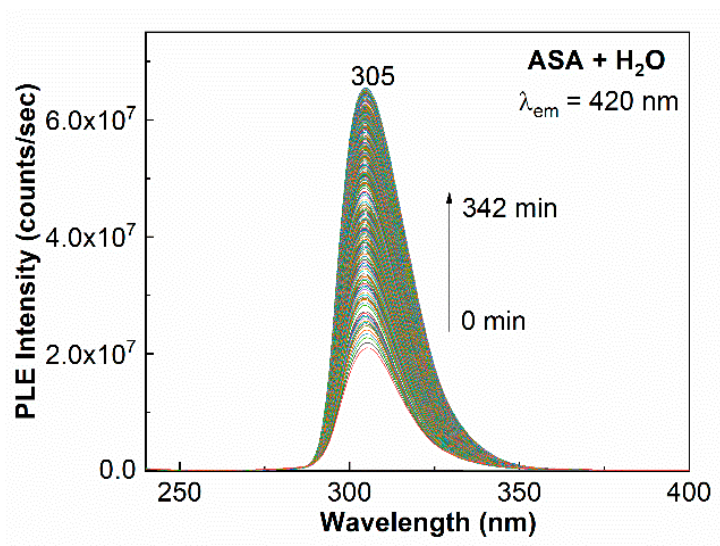

(a)

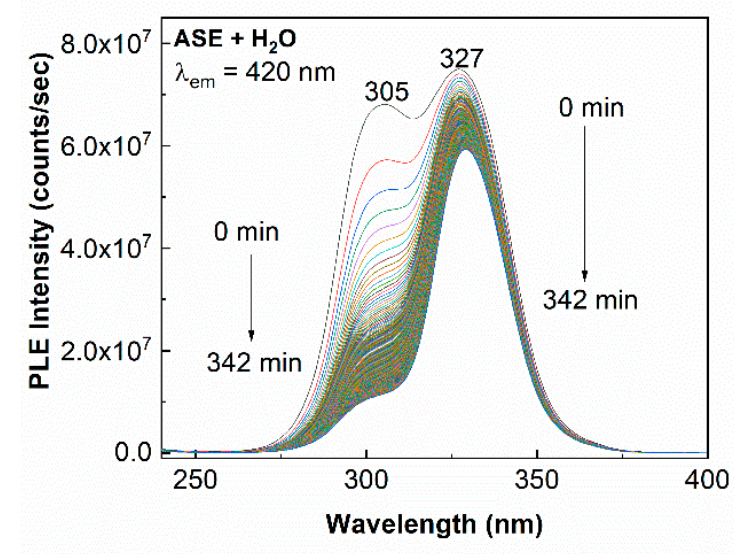

(c)

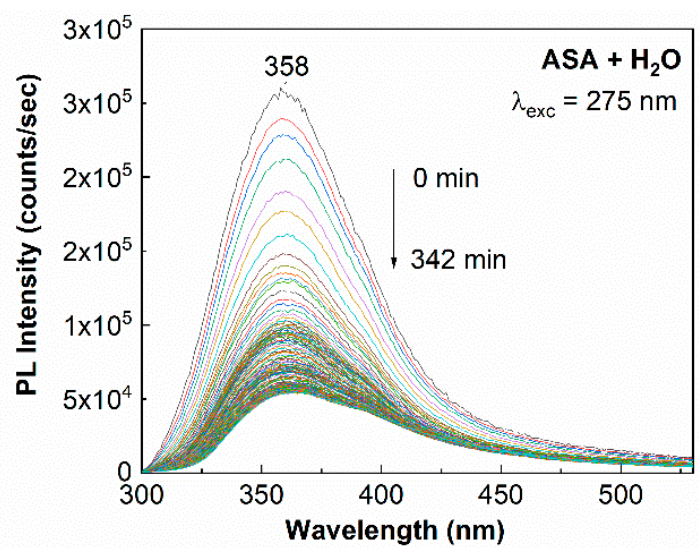

(b)

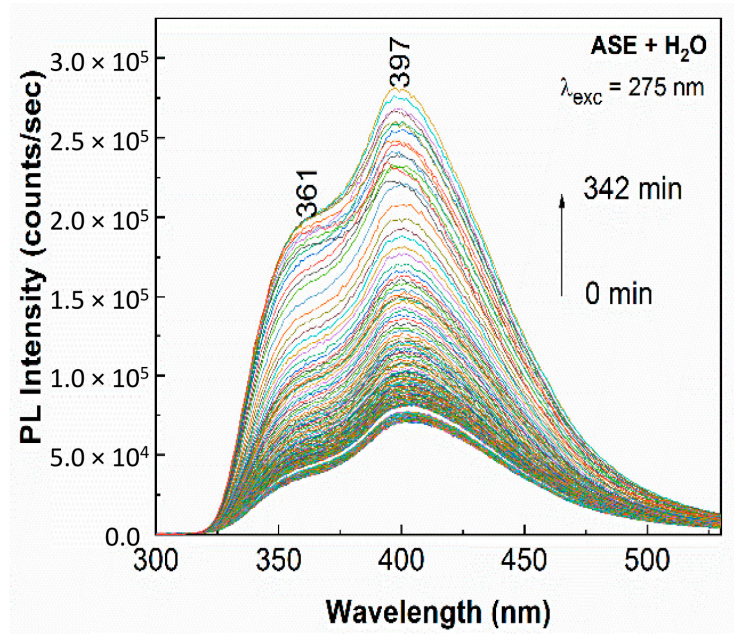

(d)

Figure 2. PLE and PL spectra recorded under the emission wavelength of $420 \mathrm{~nm}$ and the excitation wavelength of $275 \mathrm{~nm}$, respectively, of the aqueous solution of ASA $0.3 \mathrm{M}(\mathbf{a}, \mathbf{b})$ and ASE $0.3 \mathrm{M}(\mathbf{c}, \mathbf{d})$.

The exposure at the UV light, time of $342 \mathrm{~min}$, induced in: (1) the PLE spectra of ASA, a gradual increase in the intensity of the band, peaked at $305 \mathrm{~nm}$ from $2.1 \times 10^{7}$ counts $/ \mathrm{sec}$ to $6.55 \times 10^{7}$ counts/sec (Figure 2a); (2) the PL spectra of ASA, having maximum at 
$358 \mathrm{~nm}$, a gradual decrease in the intensity from $3 \times 10^{5}$ counts $/ \mathrm{sec}$ to $5.5 \times 10^{4}$ counts $/ \mathrm{sec}$ (Figure 2b); (3) the PLE spectra of ASE, a decrease of the two bands peaked at $305 \mathrm{~nm}$ and $327 \mathrm{~nm}$ from $6.81 \times 10^{7}$ counts $/ \mathrm{sec}$ and $7.5 \times 10^{7}$ counts $/ \mathrm{sec}$ to $1.13 \times 10^{7}$ counts $/ \mathrm{sec}$ and $5.93 \times 10^{7}$ counts/sec, respectively, so that the ratio between the intensities of the two bands $\left(\mathrm{I}_{305} / \mathrm{I}_{327}\right)$ varied from 0.91 to 0.19 (Figure 2c); and (4) the PL spectra of ASE, an increase in the intensity of the two emission bands at 358 and $403-400 \mathrm{~nm}$, simultaneously with a variation of the $\mathrm{I}_{358} / \mathrm{I}_{403}$ ratio from 0.48 to 0.69 (Figure $2 \mathrm{~d}$ ).

Under UV light, depending on the medium used for the dissolution of ASA, one observes that in the case of: (1) ASA in $\mathrm{PB}$ with $\mathrm{pH}=7$, an increase in the intensity of the PLE spectra from $1.68 \times 10^{8}$ counts $/$ sec to $1.88 \times 10^{8}$ counts $/$ sec occurred in the first $17 \mathrm{~min}$, followed by a decrease in intensity to $\sim 1.38 \times 10^{8}$ counts/sec, simultaneously with a gradual shift of the maximum of the PLE band from $307 \mathrm{~nm}$ to $426 \mathrm{~nm}$ (Figure 3a); (2) ASA in PB with $\mathrm{pH}=7$, the PL spectrum showed two components having maxima at $358 \mathrm{~nm}$ and $391 \mathrm{~nm}$, whose intensity gradually decreased from 43.807 counts/sec and 34.644 counts/sec to 6.612 counts/sec and 22.863 counts/sec, respectively, so that the ratio between the intensities of the two bands $\left(\mathrm{I}_{358} / \mathrm{I}_{391}\right)$ varied from $\sim 1.26$ to $\sim 0.29$ (Figure $3 b$ ); (3) ASA, which interacted with $\mathrm{NaOH}$, caused an increase in the intensity of PLE spectra from $4.81 \times 10^{7}$ counts $/ \mathrm{sec}$ to $8.34 \times 10^{7}$ counts/sec, succeeded by a decrease in the intensity up to $6.49 \times 10^{7}$ counts/sec; this variation was accompanied by a shift of the PLE band from $306 \mathrm{~nm}$ to $319 \mathrm{~nm}$ (Figure 3c); and (4) ASA interacted with $\mathrm{NaOH}$, a progressive decrease in the intensity of PL band from $4.73 \times 10^{5}$ counts $/ \mathrm{sec}$ to $2.5 \times 10^{7}$ counts $/ \mathrm{sec}$ was reported (Figure 3d).

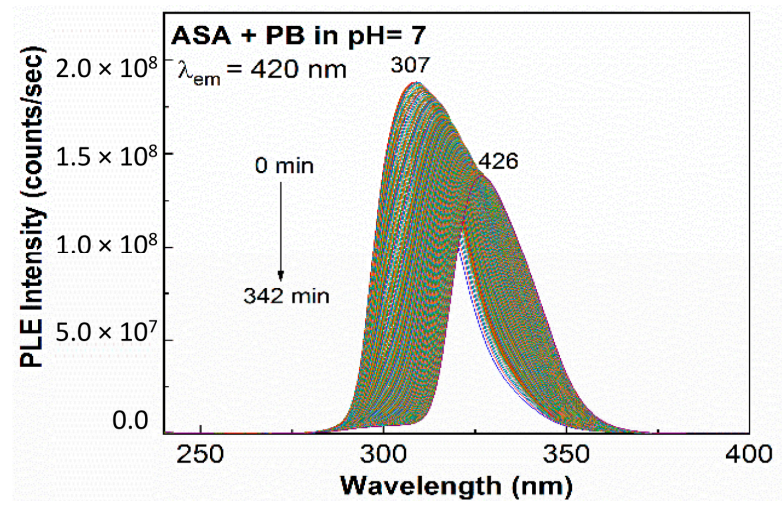

(a)

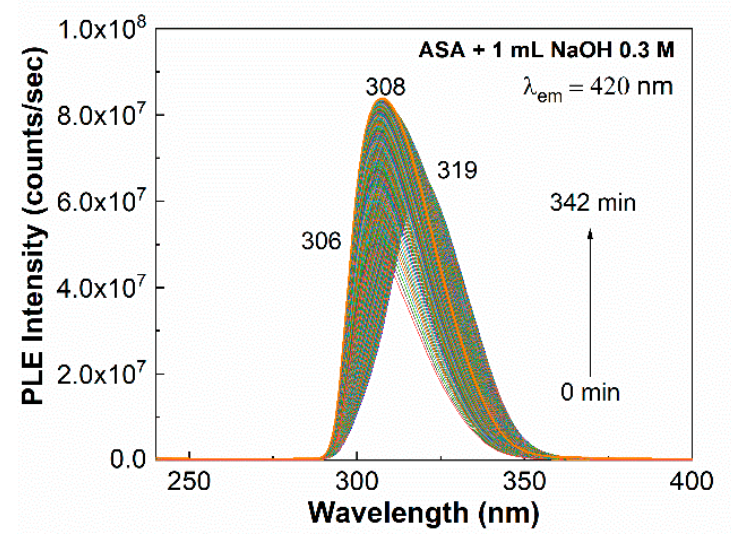

(c)

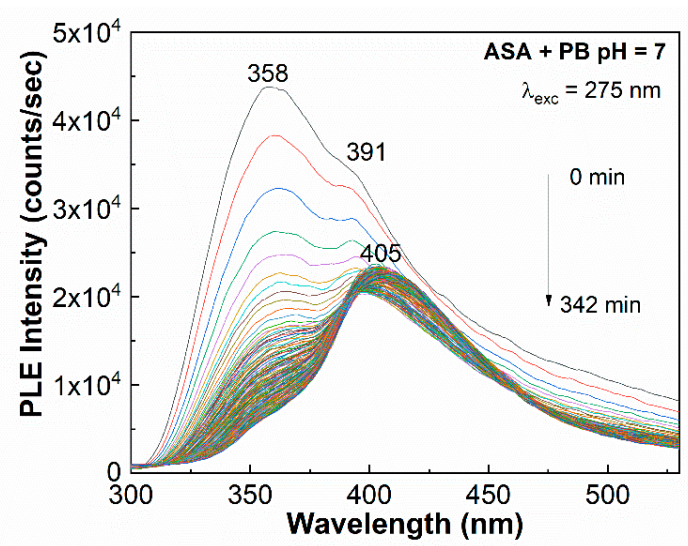

(b)

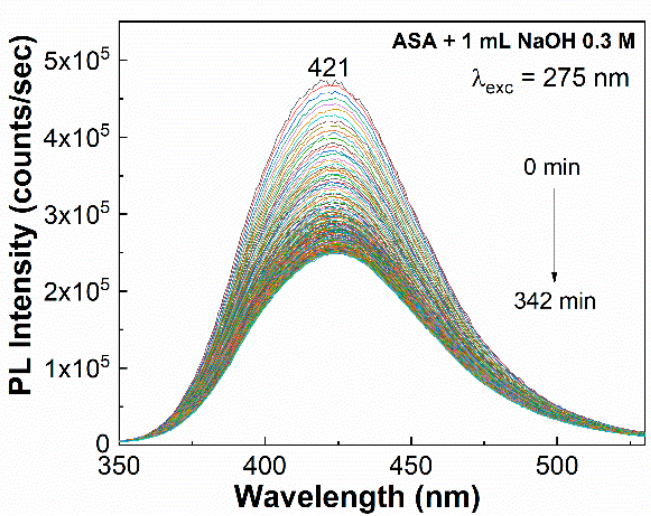

(d)

Figure 3. PLE and PL spectra of ASA in the presence of phosphate buffer $(\mathrm{PB})$ with $\mathrm{pH}=7(\mathbf{a}, \mathbf{b}$, the ASA concentration was $0.3 \mathrm{M}$ ) and after the interaction of $2 \mathrm{~mL}$ ASA $0.3 \mathrm{M}$ with $1 \mathrm{~mL} \mathrm{NaOH} 0.3 \mathrm{M}(\mathbf{c}, \mathbf{d})$. All PLE and PL spectra were recorded under the emission wavelength equal to $420 \mathrm{~nm}$ and the excitation wavelength equal to $275 \mathrm{~nm}$, respectively. 
Figure 4 highlights the dependence of the PLE and PL spectra of ASE as function of the $\mathrm{PB} \mathrm{pH}$ value.

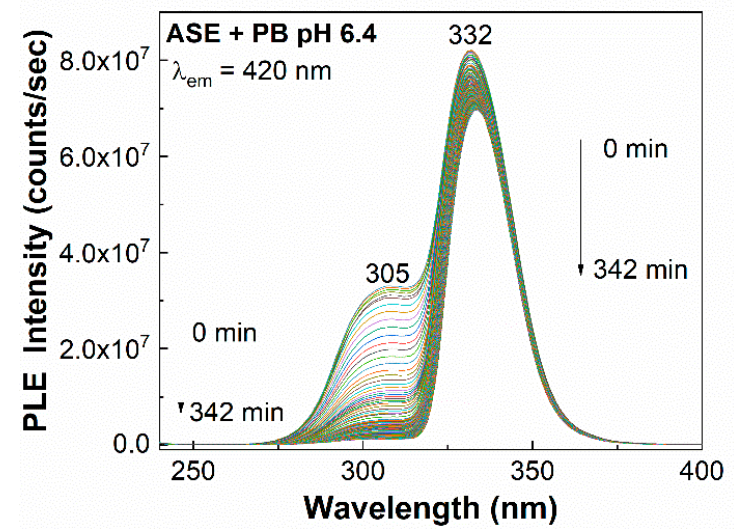

(a1)

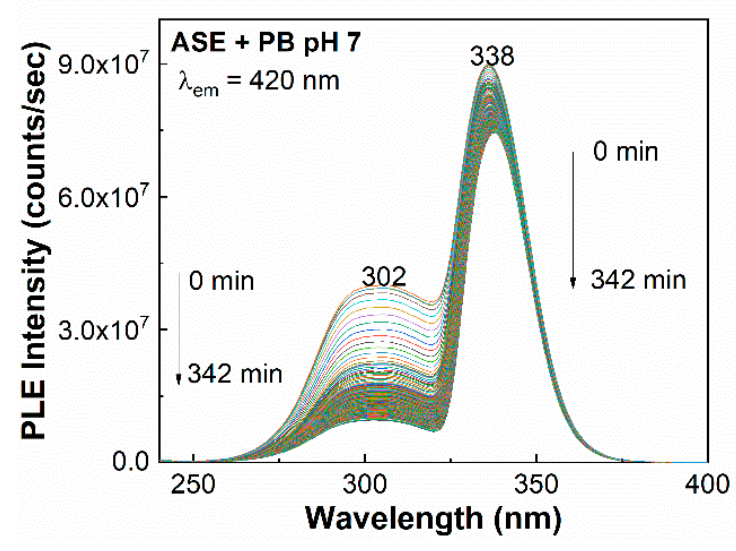

(b1)

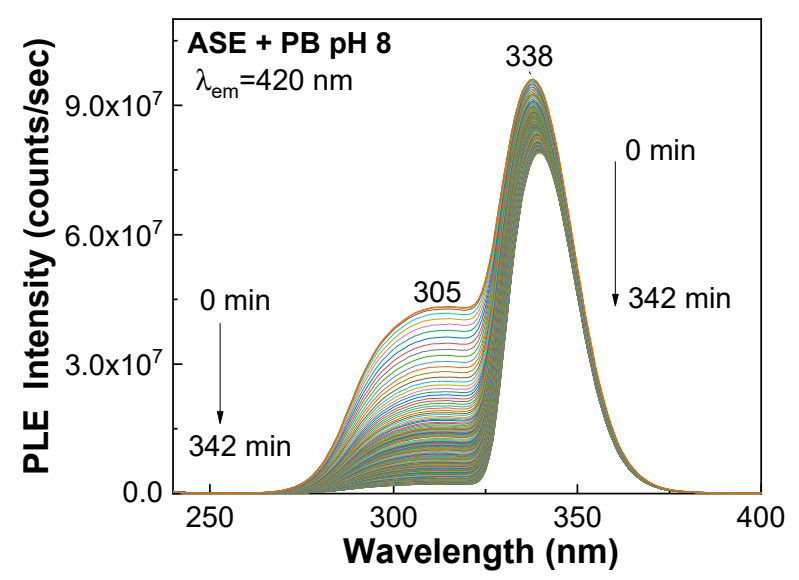

(c1)

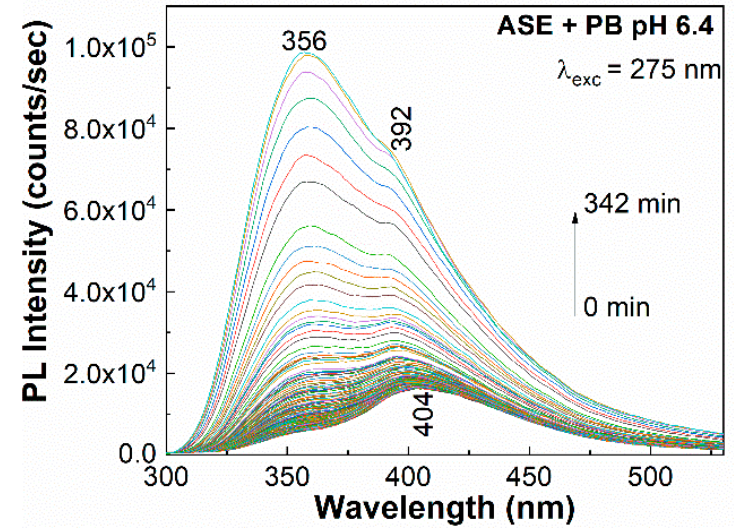

(a2)

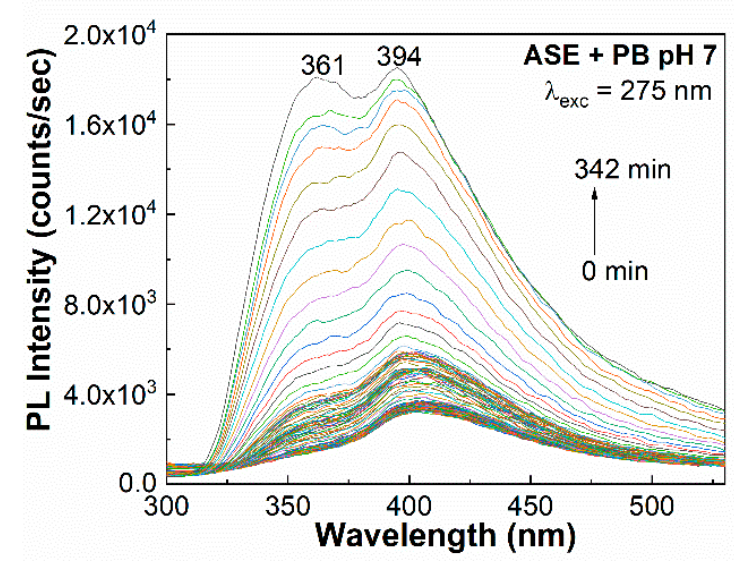

(b)

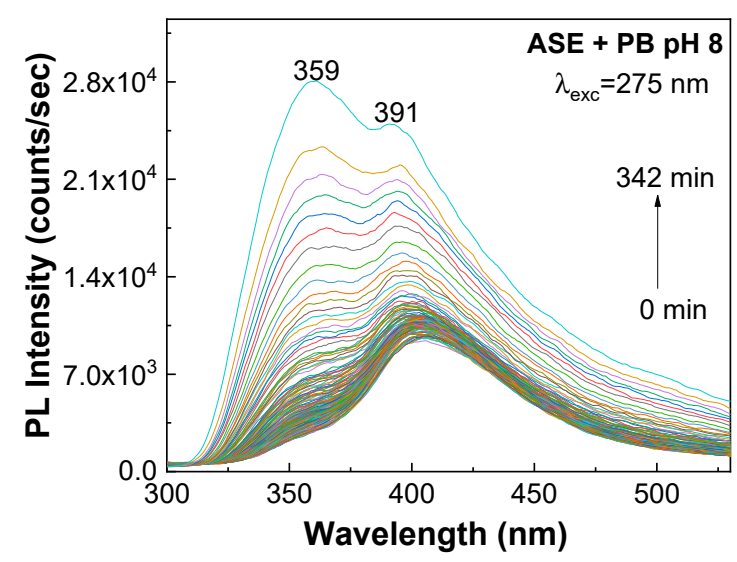

(c2)

Figure 4. PLE (1) and PL (2) spectra of ASE in the presence of PB with pH equal to $6.4\left(\mathbf{a}_{1}, \mathbf{a}_{2}\right), 7\left(\mathbf{b}_{1}, \mathbf{b}_{2}\right)$ and 8 ( $\left.\mathbf{c}_{1}, \mathbf{c}_{2}\right)$. PLE and PL spectra were recorded at the emission wavelength equal to $420 \mathrm{~nm}$ and the excitation wavelength equal to $275 \mathrm{~nm}$, respectively. 
As increasing the $\mathrm{pH}$ from 6.4 to 7 and 8 in Figure $4 \mathrm{a}_{1}, \mathrm{~b}_{1}, \mathrm{c}_{1}$ was highlighted: (1) Prior to exposure of the ASE solution at UV light, all PLE spectra were characterized by an intense band with the maximum at $332-338 \mathrm{~nm}$ having the intensity equal to $8.18 \times 10^{7} \mathrm{counts} / \mathrm{sec}$, $9 \times 10^{7}$ counts $/ \mathrm{sec}$, and $9.61 \times 10^{7}$ counts $/ \mathrm{sec}$, accompanied by another band at 305$310 \mathrm{~nm}$ whose intensity was equal to $3.26 \times 10^{7}$ counts $/ \mathrm{sec}, 4 \times 10^{7}$ counts $/ \mathrm{sec}$, and $4.32 \times 10^{7}$ counts $/ \mathrm{sec}$. Thus, before exposure of ASE in PB with $\mathrm{pH}$ of $6.4,7$, and 8 , the ratio between the intensities of the bands with maxima at 302-305 nm and 332-338 nm $\left(\mathrm{I}_{302-305} / \mathrm{I}_{332-338}\right)$ was equal to $0.4,0.44$, and 0.45 , respectively. (2) As the exposure time of ASE in PB with a pH equal to 6.4, 7, and 8 to UV light increased up to $342 \mathrm{~min}$, in Figure $4 \mathrm{a}_{1}, \mathrm{~b}_{1}, \mathrm{c}_{1}$ a decrease in the intensity of the band at 332-338 nm was observed up to $6.98 \times 10^{7}$ counts $/ \mathrm{sec}, 7.45 \times 10^{7}$ counts $/ \mathrm{sec}$, and $8 \times 10^{7}$ counts $/ \mathrm{sec}$, while the intensity of PLE band at 305-310 nm was equal to $1.23 \times 10^{6}$ counts/ sec, $9.55 \times 10^{6}$ counts $/ \mathrm{sec}$, and $2.05 \times 10^{7}$ counts $/ \mathrm{sec}$, respectively. After exposure at UV light time of $342 \mathrm{~min}$ of ASE in $\mathrm{PB}$ with $\mathrm{pH}$ of $6.4,7$, and 8 , the $\mathrm{I}_{302-305} / \mathrm{I}_{332-338}$ ratio was equal to $0.017,0.016$, and 0.12 . According to Figure $4 a_{2}, b_{2}, c_{2}$, the following variations were seen: (1) Before exposure of ASE in PB with pH equal to 6.4, 7, and 8, to UV light, all PL spectra were characterized by two bands having the maxima at 356-361 nm and 403-404 nm, the ratio between the intensities of the two PL bands being equal to $0.3,0.4$, and 0.3 , respectively. (2) After the exposure ASE in PB with $\mathrm{pH}$ equal to 6.4, 7, and 8, to UV light, a shift of the emission band at $403-404 \mathrm{~nm}$ at 391-394 nm took place. As increasing the exposure time at UV light up to $342 \mathrm{~min}$, the ratio between the intensities of the PL bands at 356-361 nm and 391-394 nm became equal to $1.3,1$, and 1.1 , respectively.

Similar variations were reported when the aqueous solution of ASE $0.3 \mathrm{M}$ interacted with the solution of $\mathrm{NaOH} 0.3 \mathrm{M}$. Figure 5 is relevant in this sense.

A careful analysis of Figure $5 a_{1}, b_{1}, c_{1}$, in contrast with Figure $2 c$, highlighted the following variations: (1) In the initial state, i.e., before exposure at UV light, as weight of $\mathrm{NaOH}$ increased in the presence of the same ASE weight, the intensity of the band at $306 \mathrm{~nm}$ decreased, so that the ratio between the intensities of the bands at $305-309 \mathrm{~nm}$ and $335-343 \mathrm{~nm}$ $\left(\mathrm{I}_{305-309} / \mathrm{I}_{335-343}\right)$ was changed from 0.91 (Figure $2 \mathrm{c}$ ) to 0.8 (Figure $5 \mathrm{a}_{1}$ ), 0.65 (Figure $5 \mathrm{~b}_{1}$ ), and 0.35 (Figure $5 c_{1}$ ). (2) As increasing the exposure time to UV light, a significant decrease in the intensity of the band at 305-309 nm was seen, the fact which induced a change in the $\mathrm{I}_{305-309} / \mathrm{I}_{335-343}$ ratio from 0.19 (Figure $2 \mathrm{c}$ ) to 0.14 (Figure $5 \mathrm{a}_{1}$ ), 1.37 (Figure $5 \mathrm{~b}_{1}$ ), and 1.5 (Figure $5 c_{1}$ ). These changes were accompanied in Figure $5 a_{2}, b_{2}, c_{2}$ by the following variations: (1) Before exposure to UV light, as an increasing in the weight of $\mathrm{NaOH}$ added to the ASE, a decrease in the intensity of the PL band at $405-406 \mathrm{~nm}$ from $7.6 \times 10^{6}$ counts $/ \mathrm{sec}$ (Figure $5 a_{2}$ ) to $1.7 \times 10^{6}$ counts $/ \mathrm{sec}$ (Figure $5 b_{2}$ ) and $4.2 \times 10^{4}$ counts $/ \mathrm{sec}\left(\right.$ Figure $5 c_{2}$ ) took place. (2) After $342 \mathrm{~min}$ of exposure to UV light, the intensity of the PL spectra in Figure 5 became equal to $1.5 \times 10^{6}$ counts $/ \sec$ (Figure $5 a_{2}$ ), $2.9 \times 10^{6}$ counts $/ \sec$ (Figure $5 b_{2}$ ), and $2.1 \times 10^{6}$ counts $/ \mathrm{sec}$ (Figure $5 \mathrm{c}_{2}$ ). The ASA hydrolysis reactions as function of the $\mathrm{pH}$ range were studied from the point of view of the activation energy, as from 1952 [40]. We noted that the variation of PLE and PL spectra, above reported, originated in the reactions shown in Scheme 1. Thus, (1) Reaction 1 in Scheme 1 showed chemical process that can be invoked in the case of Figures $2,3 a, b$ and $4 b_{1}, b_{2}$, i.e., when the aqueous solutions of ASA or ASE have $\mathrm{pH}=7$; (2) Reaction 2 in Scheme 1 illustrated chemical process that induces variations, shown in Figure $4 a_{1}, a_{2}$; (3) Reaction 3 in Scheme 1 highlighted the chemical process that led to changes shown in Figure $4 \mathrm{c}_{1}, \mathrm{c}_{2}$; and (4) reactions 4 and 5 in Scheme 1 evidenced the reaction of ASA with $\mathrm{NaOH}$, shown in Figures $3 \mathrm{c}, \mathrm{d}$ and 5 . According to Scheme 1, the reaction products corresponded to salicylic acid (SAL), acetic acid, sodium salicylate, and sodium acetate. 


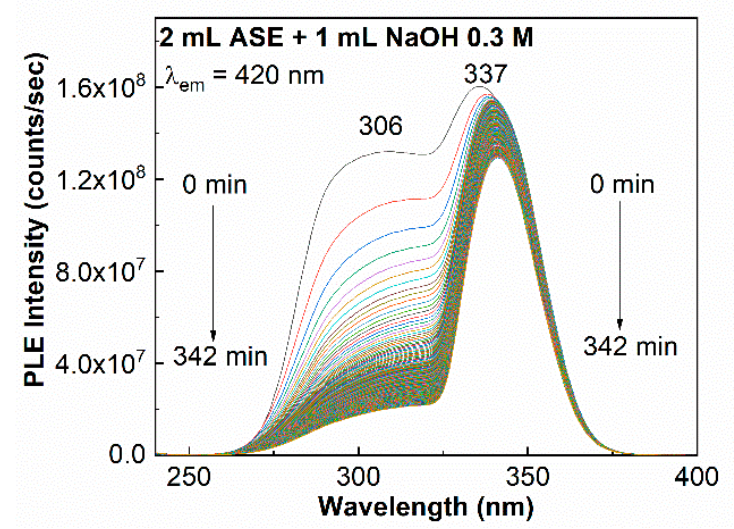

(a1)

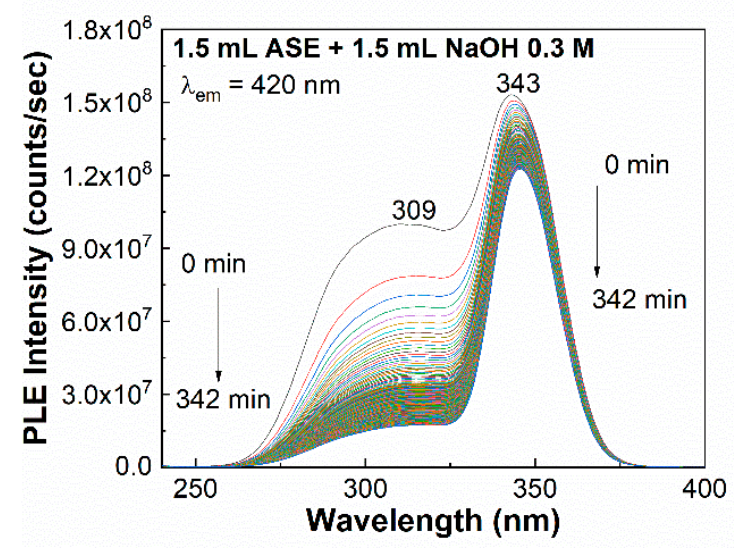

(b1)

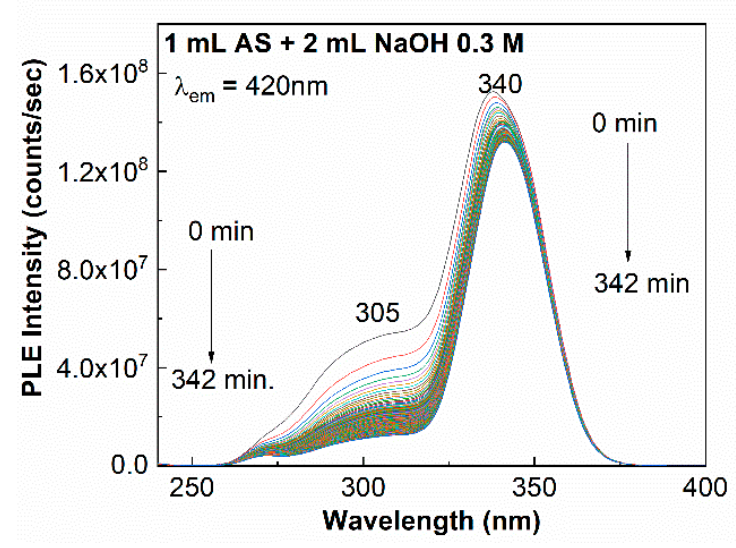

(c1)

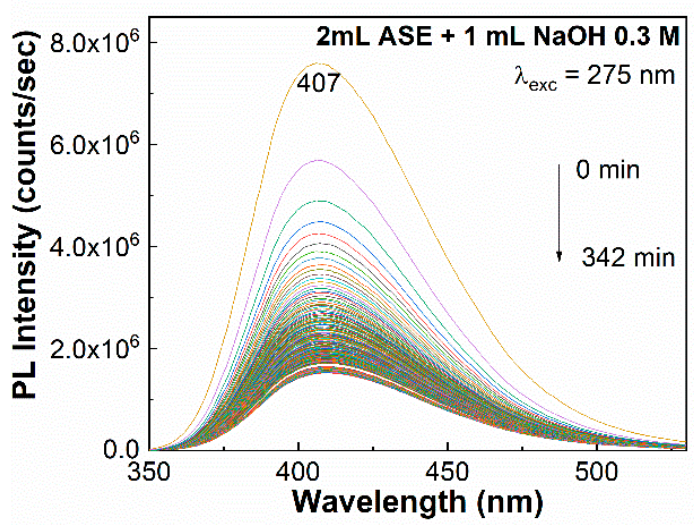

(a2)

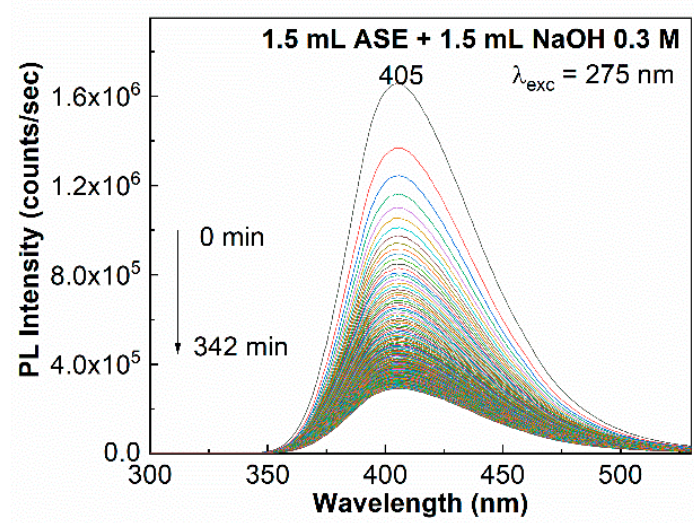

(b2)

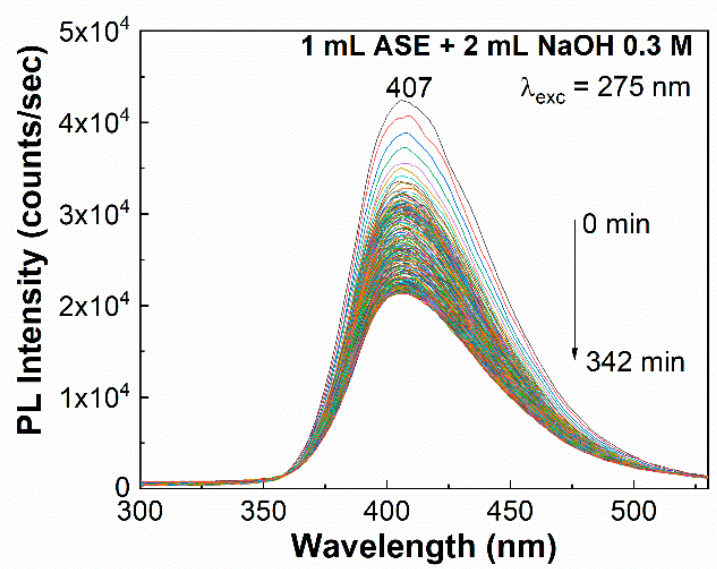

(c2)

Figure 5. PLE (1) and PL (2) spectra of ASE interacted with NaOH 0.3 M in the volumetric ratio: 2:1 ( $\left.\mathbf{a}_{1}, \mathbf{a}_{2}\right), 1.5: 1.5\left(\mathbf{b}_{1}, \mathbf{b}_{\mathbf{2}}\right)$, and 1:2 $\left(\mathbf{c}_{1}, \mathbf{c}_{2}\right)$. PLE and PL spectra were recorded at the emission wavelength equal to $420 \mathrm{~nm}$ and the excitation wavelength equal to $275 \mathrm{~nm}$, respectively.

Taking into account Scheme 1, we think that the different behavior of the PL spectra of ASA and ASE, during the exposure to UV light, originated also in a phototautomerization process of SAL [41], a compound, which in the commercial drugs, there is up to $0.1 \%$ [42]. 


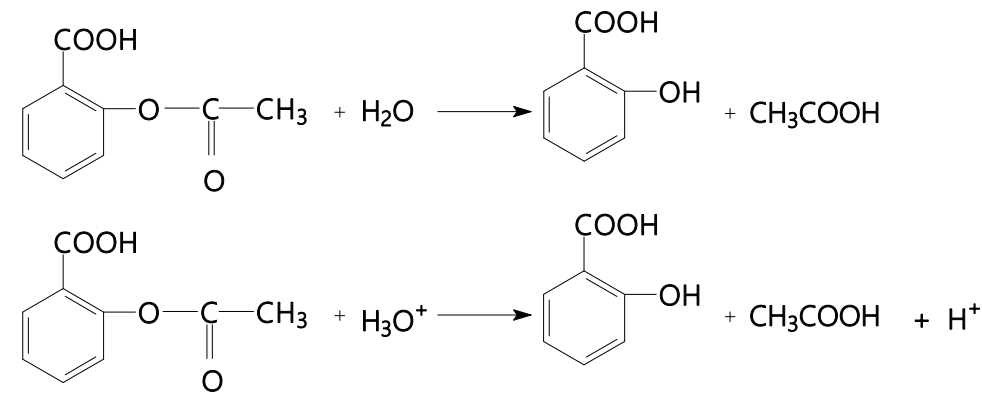

(1)<smiles>CC(=O)Oc1ccccc1C(=O)O</smiles><smiles></smiles>

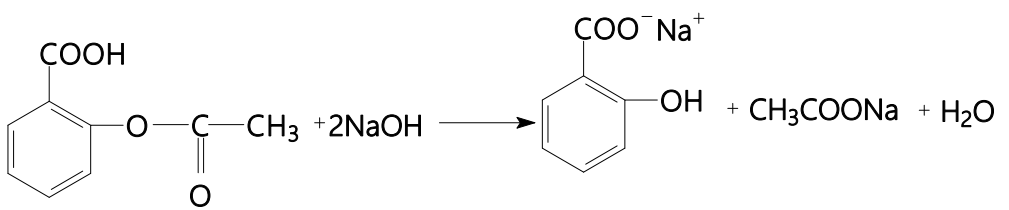

Scheme 1. The chemical reactions of ASA with $\mathrm{H}_{2} \mathrm{O}$ and $\mathrm{NaOH}$.

Figures 6 and 7 show the Raman and FTIR spectra of AS in the initial state and after the interaction with $\mathrm{NaOH}$. Figure 6a shows the Raman spectrum of ASA. The main Raman lines of ASA peaked at 557, 646-754, 787, 1045, 1157, 1192, 1260-1301, 1435, $1608,1631,1753,2945$, and $3076 \mathrm{~cm}^{-1}$. They were assigned to the following vibrational modes: $\mathrm{CO}_{2}$ rocking vibration + bending vibrations for $\mathrm{CO}_{2}$, torsion benzene ring, $\mathrm{C}-$ $\mathrm{H}$ out-of-plane bending, benzene breathing, $\mathrm{C}-\mathrm{C}$ stretching $+\mathrm{C}-\mathrm{H}$ in-plane bending in benzene, $\mathrm{C}-\mathrm{H}$ in-plane bending in benzene, $\mathrm{C}-\mathrm{C}$ stretching $+\mathrm{C}-\mathrm{H}$ in-plane bending in benzene, $\mathrm{O}-\mathrm{H}$ in-plan bending, $\mathrm{C}-\mathrm{C}$ stretching in benzene ring, $\mathrm{C}=\mathrm{C}$ stretching in benzene ring, $\mathrm{C}=\mathrm{O}$ stretching, $\mathrm{CH}_{3}$ asymmetrical stretching, and $\mathrm{CH}_{3}$ symmetrical stretching, respectively [24,43]. According to Figure $6 \mathrm{~b}$, the following changes were observed when ASA interacted with $\mathrm{NaOH}$ : (1) a downshift of the Raman lines from $557 \mathrm{~cm}^{-1}$ to $553 \mathrm{~cm}^{-1}$; (2) a change of the ratio between the intensities of Raman lines peaked at $1608 \mathrm{~cm}^{-1}$ and 557 $\mathrm{cm}^{-1}\left(\mathrm{I}_{1608} / \mathrm{I}_{557}\right)$ or $2945 \mathrm{~cm}^{-1}\left(\mathrm{I}_{1608} / \mathrm{I}_{2945}\right)$ from 7.5 and 5.9 to 4.62 and 2.97 , respectively; and (3) an upshift of the Raman line from $3076 \mathrm{~cm}^{-1}$ to $3081 \mathrm{~cm}^{-1}$. These experimental facts indicate change in the molecular structure of ASA when this interacts with $\mathrm{NaOH}$.

Additional arguments concerning the interaction of ASA with $\mathrm{NaOH}$ are shown in Figure 7.

The main IR bands of ASA peaked at 703-754-802-839, 914, 970, 1012-1093, 1182, $1217,1304,1367,1415,1456,1605,1678,1751$, and $3674 \mathrm{~cm}^{-1}$ (Figure 7a), with these being assigned to the vibrational modes: $\mathrm{C}-\mathrm{H}$ out-of-plane bending, $\mathrm{O}-\mathrm{H}$ out-of-plane bending, $\mathrm{O}-$ $\mathrm{H}$ asymmetrical bending, in-plane bending $\mathrm{C}-\mathrm{H}+$ stretching $\mathrm{C}-\mathrm{O}$ in ester, in-plane bending $\mathrm{C}-\mathrm{H}$, in-plane bending $\mathrm{C}-\mathrm{H}+$ stretching $\mathrm{C}-\mathrm{O}$, stretching $\mathrm{C}-\mathrm{O}$, symmetrical deformation of $\mathrm{CH}_{3}$, O-H out-of-plane bending, asymmetrical deformation of $\mathrm{CH}_{3}$, stretching $\mathrm{C}=\mathrm{C}$ in benzene ring, stretching $\mathrm{C}=\mathrm{O}$ in ester group, and stretching $\mathrm{C}=\mathrm{O}$ in acid group and $\mathrm{OH}$ [24]. After a careful analysis of Figure 7a,b, the following changes were observed: (1) a shift of the IR band from $1751 \mathrm{~cm}^{-1}$ to $1745 \mathrm{~cm}^{-1}$; (2) a decrease in the absorbance of the IR band peaked at 1678-1680 $\mathrm{cm}^{-1}$, which induced a diminution of the ratio between the absorbances of the IR bands peaked at $1678-1680 \mathrm{~cm}^{-1}$ and $1751-1745 \mathrm{~cm}^{-1}$ from 1.58 to 1.05; and (3) the gradual decrease in the absorbance of the IR bands in the spectral ranges 
$1000-1100 \mathrm{~cm}^{-1}$ assigned to the vibrational mode in-plane bending C-H + stretching C-O in ester as well as of the IR bands peaked at $1304 \mathrm{~cm}^{-1}$. These variations indicated the diminution of the weight of the ester groups, as a consequence of the reactions 4 and 5 shown in Scheme 1.

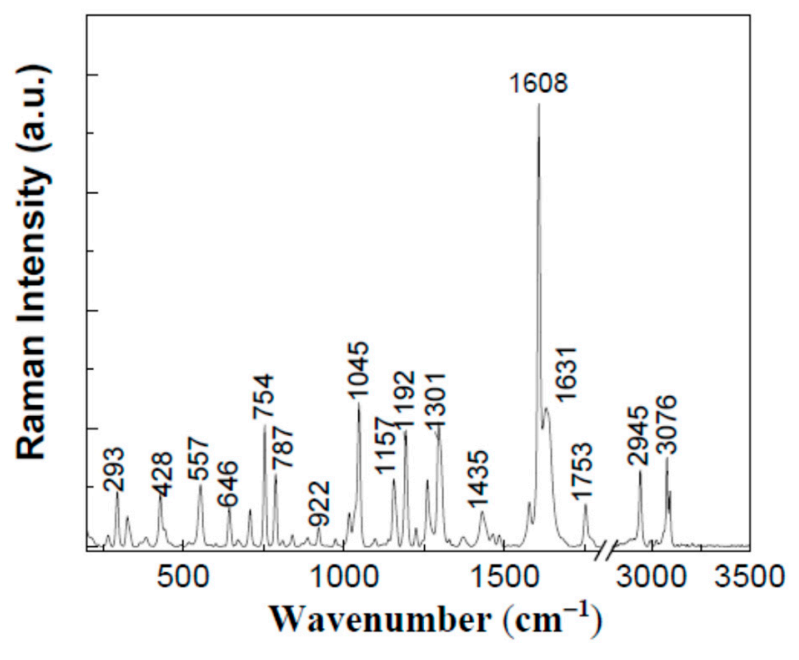

(a)

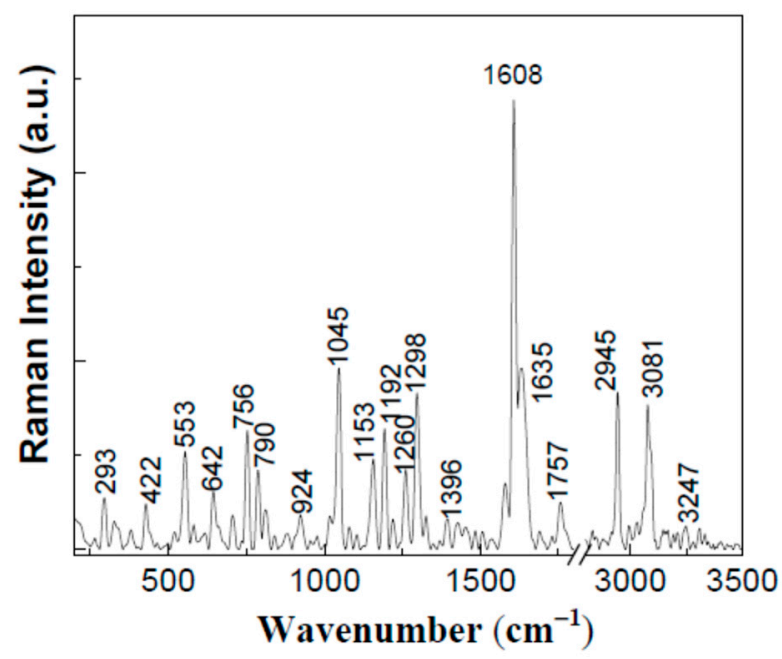

(b)

Figure 6. The Raman spectra of ASA in the initial state (a) and after the interaction with $\mathrm{NaOH}(\mathbf{b})$.

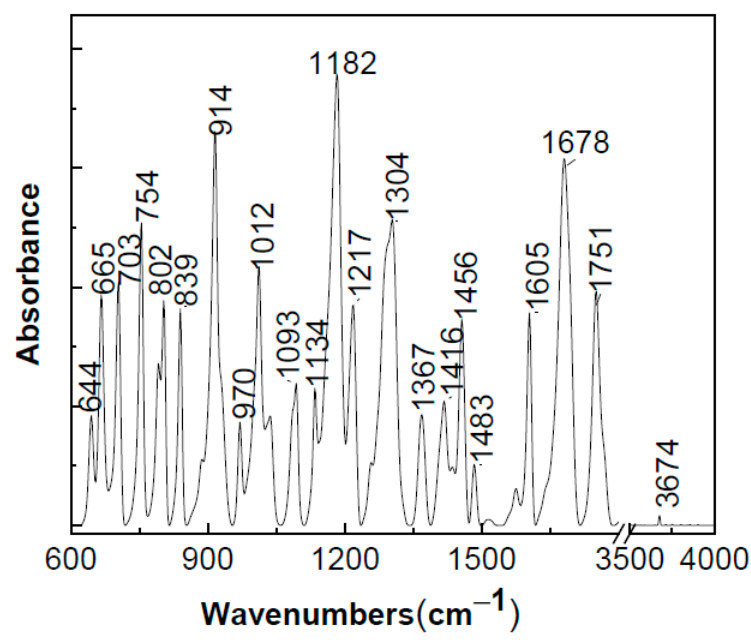

(a)

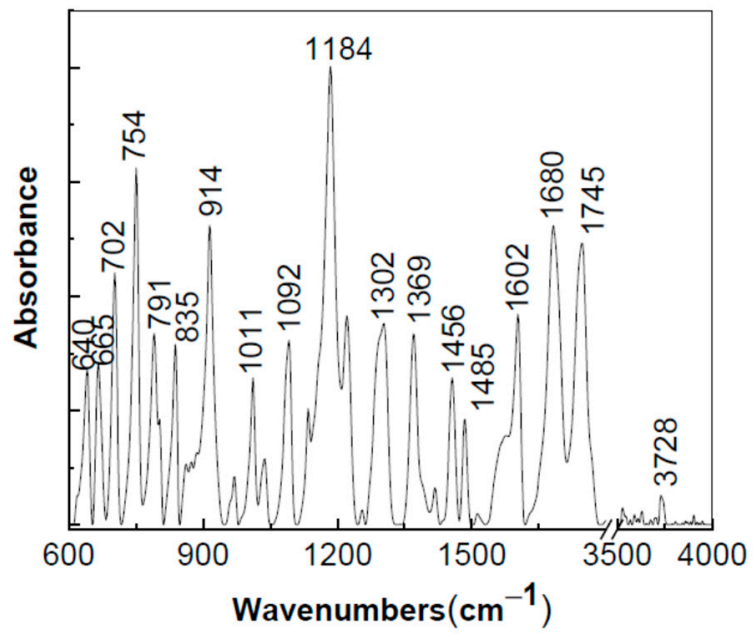

(b)

Figure 7. The IR spectra of ASA in the initial state (a) and after interaction with $\mathrm{NaOH}(\mathbf{b})$.

Figure 8 highlights the dependence of PLE and PL spectra of the aqueous solution of ASA $0.3 \mathrm{M}$ as function of the temperature.

According to Figure $8 \mathrm{a}, \mathrm{b}$, by the heating of the aqueous solution of ASA $0.3 \mathrm{M}$ up to $50{ }^{\circ} \mathrm{C}$ one observed that the intensity of the PLE and PL spectra became equal to $1.6 \times 10^{6}$ counts $/ \mathrm{sec}$ and $5.23 \times 10^{3}$ counts $/ \mathrm{sec}$, respectively. These values were smaller in the comparison with those reported immediately after preparing the solution, i.e., $2.1 \times 10^{7}$ counts $/ \mathrm{sec}$ (Figure 2a) and $3 \times 10^{5}$ counts $/ \mathrm{sec}$ (Figure 2b). The gradual cooling of the aqueous solution of ASA $0.3 \mathrm{M}$ from $50{ }^{\circ} \mathrm{C}$ to $28^{\circ} \mathrm{C}$ induced an increase in the intensity of: (1) the PLE spectra from $1.6 \times 10^{6}$ counts/sec to $2.9 \times 10^{6}$ counts/sec (Figure 8a) and (2) the PL spectra of ASA, from $5.2 \times 10^{3}$ counts $/ \mathrm{sec}$ to $1.22 \times 10^{4}$ counts $/ \mathrm{sec}$ (Figure $8 \mathrm{~b}$ ). 
These results demonstrated that the heating-cooling process is not a reversible one, the heating favoring the formation of SAL.

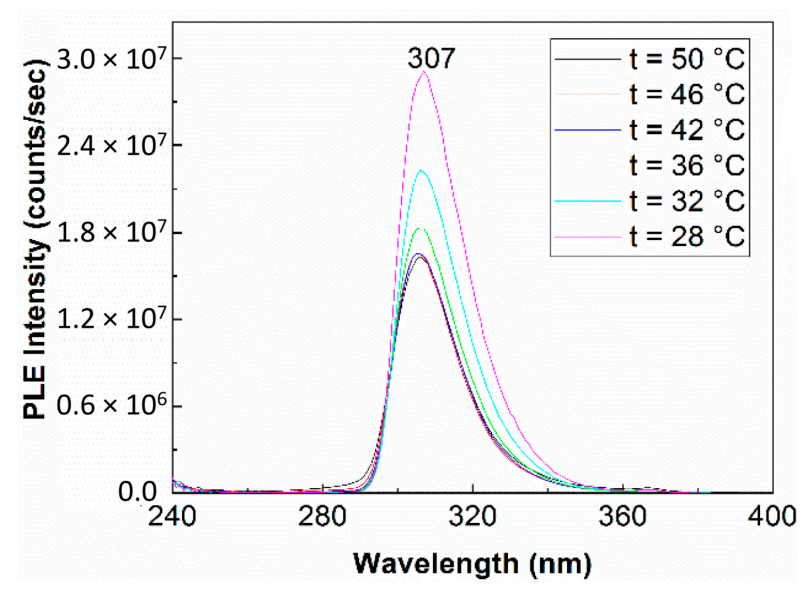

(a)

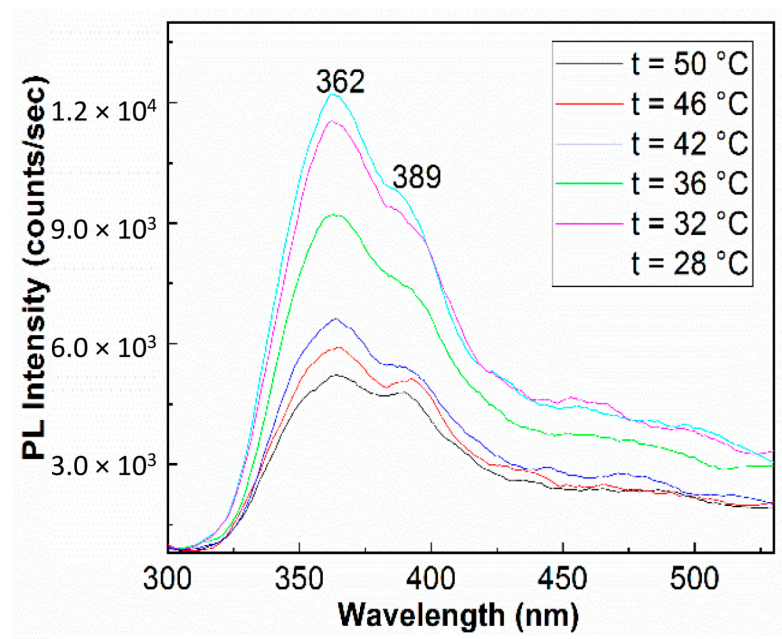

(b)

Figure 8. The dependence of the PLE (a) and PL (b) spectra of the aqueous solution of ASA 0.3 M with the temperature. All PLE spectra were recorded at the emission wavelength of $420 \mathrm{~nm}$, while the PL spectra were recorded at the excitation wavelength of $275 \mathrm{~nm}$.

In order to further argue the optical processes of ASA that take place in the temperature range $28-50{ }^{\circ} \mathrm{C}$, Figure 9 shows the dependence of IR spectra of ASA with temperature. The following changes are observed in Figure 9 as increasing the temperature: (1) a progressive decrease in the absorbance of the IR bands peaked at $1012 \mathrm{~cm}^{-1}$ assigned to the vibrational mode in-plane bending C-H + stretching C-O in ester group [24]; (2) change the ratio between the absorbances of the IR bands peaked at $1680 \mathrm{~cm}^{-1}$ and $1751 \mathrm{~cm}^{-1}$, assigned to the vibrational modes of stretching $\mathrm{C}=\mathrm{C}$ in benzene ring and stretching $\mathrm{C}=\mathrm{O}$ in ester group [24], from 1.58 to 1.35; and (3) a gradual decrease in the ratio between the absorbance of the IR bands situated at $914 \mathrm{~cm}^{-1}$ and $1680 \mathrm{~cm}^{-1}$, attributed to the vibrational modes of $\mathrm{O}-\mathrm{H}$ out-of-plane bending and stretching $\mathrm{C}=\mathrm{C}$ in benzene ring [24], from 1.081 to 0.88 , simultaneously with the increase of the absorbance of the IR bands peaked at $1512 \mathrm{~cm}^{-1}$ and $1546 \mathrm{~cm}^{-1}$, assigned to the vibrational mode phenyl-C stretching + deformation of phenyl-H and symmetric deformation of $\mathrm{CH}_{3}$ group [44].The first two variations were also reported when ASA was interacted with $\mathrm{NaOH}$, when SAL and $\mathrm{CH}_{3} \mathrm{COOH}$ resulted.

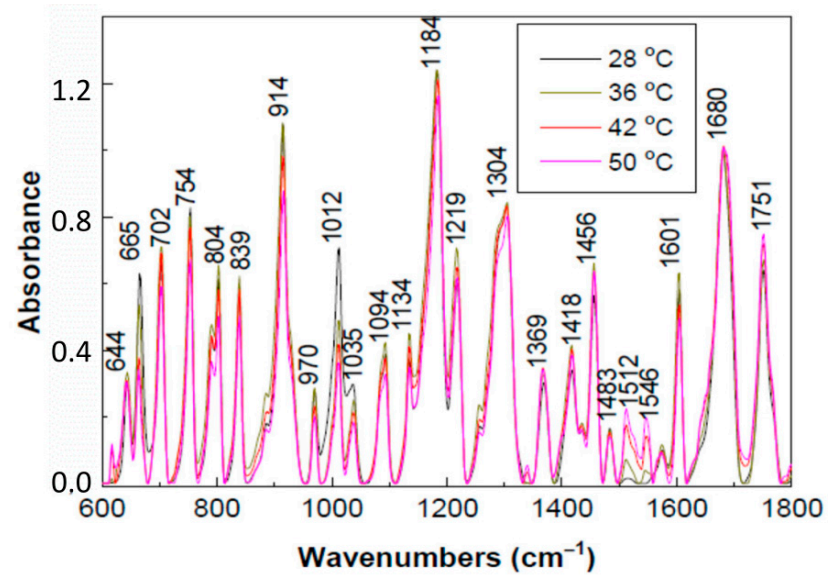

Figure 9. The dependence of the IR spectra of ASA with the temperature. 
The decrease of the ratio between the absorbance of the IR bands situated at $914 \mathrm{~cm}^{-1}$ and $1680 \mathrm{~cm}^{-1}$ as well as with the increase of the absorbance of the IR bands peaked at $1512 \mathrm{~cm}^{-1}$ and $1546 \mathrm{~cm}^{-1}$ indicated a diminution of the $\mathrm{OH}$ groups simultaneously with the increase of the weight of the phenyl and $\mathrm{CH}_{3}$ groups. These changes can be explained only if we accept the generation of a secondary product of the type of the organic acid anhydride (R-CO-O-CO-R, where $\mathrm{R}$ corresponds to $\mathrm{C}_{6} \mathrm{H}_{4}-\mathrm{O}-\mathrm{CO}-\mathrm{CH}_{3}$ ) took place. These preliminary results on ASA changes with temperature require, in the next stage, additional clinical trials to consider, in addition, the electrolyte imbalance in the case of patients with various gastrointestinal, cardiovascular, and lung diseases [45].

\section{Materials and Methods}

Acetylsalicylic acid (ASA), $\mathrm{NaOH}, \mathrm{Na}_{2} \mathrm{HPO}_{4}$, and $\mathrm{NaH}_{2} \mathrm{PO}_{4}$ were purchased from Sigma Aldrich. Sodium hydroxide $(\mathrm{NaOH}), 98 \%$ purity, was purchased from Alfa Aesar. The tablets of aspirin (ASE), having as (1) active compound $500 \mathrm{mg}$ ASA and (2) excipients, corn starch and cellulose powder, were bought from local pharmacies.

The PB solutions with $\mathrm{pH}$ equal to $6.4,7$, and 8 were prepared using the aqueous solutions of $\mathrm{Na}_{2} \mathrm{HPO}_{4}$ and $\mathrm{NaH}_{2} \mathrm{PO}_{4}$. In order to highlight the photodegradation of ASA and ASE, we prepared (1) an aqueous solution of ASA 0.3 M and (2) another of AS with the concentration of $\sim 0.3 \mathrm{M}$ by dissolving of a tablet of ASE, having as active compound $500 \mathrm{mg}$ ASA in $10 \mathrm{~mL}$ distilled water or PB, under ultrasonication, for $10 \mathrm{~min}$. In order to remove water-insoluble excipients, a successive filtration was carried out.

The photodegradation of ASA and ASE was highlighted in this work by hydrolysis reaction of ASA or ASE with alkaline media such as the aqueous solutions of $\mathrm{NaOH} 0.3 \mathrm{M}$.

The photodegradation of ASA and ASE under UV light, for $362 \mathrm{~min}$, was studied by photoluminescence, IR spectroscopy, and Raman scattering. In the case of the last two analyses, the photodegradation studies were carried out with a mercury-vapor lamp having the power of $350 \mathrm{~W}$, purchased from Newport company (Irvine, CA, USA). The irradiation power was of $4.46 \mathrm{~mW} / \mathrm{cm}^{2}$.

The photoluminescence (PL) and photoluminescence excitation (PLE) spectra of the ASA and ASE solutions were recorded in right-angle geometry, at room temperature, using a Fluorolog -3 spectrometer, model FL3-22, from Horiba Jobin Yvon, which was endowed with a Xe lamp with the power of $450 \mathrm{~W}$, purchased from Newport company (Irvine, CA, USA). The irradiation power was $4.42 \mathrm{~mW} / \mathrm{cm}^{2}$.

The devices used for the exposure to UV light of the samples were equipped with a cooling system. Raman spectra of ASA in the initial state and after the interaction with $\mathrm{NaOH}$ were recorded, at the excitation wavelength of $1064 \mathrm{~nm}$, with a FT Raman spectrophotometer, RFS100S model, from Bruker ((Bruker Optik GmbH, Ettlingen, Germany)).

IR spectra of ASA in the initial state and after the interaction with $\mathrm{NaOH}$ were recorded with a FTIR spectrophotometer, Vertex 70 model, from Bruker (Billerica, MA, USA).

\section{Conclusions}

In this work, new results are reported concerning the photodegradation of ASA and ASE, by PL, Raman scattering, and FTIR spectroscopy. Our results allow us to conclude that (1) PL is a valuable tool to highlight the presence of SAL in commercial drugs; (2) the monitoring of the hydrolysis reaction of the solutions of ASA $0.3 \mathrm{M}$ in PB with pH equal to $6.4,7$, and 8 induced a gradual increase in the intensity of PLE spectra simultaneously with a progressive decrease of the intensity of PL spectra; (3) the hydrolysis reaction of the solutions of ASE 0.3 M in PB with pH equal to 6.4, 7, and 8 showed a different behavior, as a consequence of the presence of SAL, when a phototautomerization process took place, too; (4) the interaction of ASA with $\mathrm{NaOH}$ led to a decrease of the ester groups in the favor of carboxylic groups, as shown by Raman scattering and FTIR spectroscopy; and (5) considering the smaller intensities of the PLE and PL spectra of the aqueous solution of ASA after the heating-cooling process, an irreversible character was invoked in this case. 
Author Contributions: Conceptualization, M.B. and C.S.; methodology, M.B.; validation, M.B.; investigation, M.D., M.I., and M.B.; writing-original draft preparation, M.D. and M.B.; writingreview and editing, M.B. and A.C.I.; supervision, M.B. All authors have read and agreed to the published version of the manuscript.

Funding: This work was funded by the project co-funded by the European Regional Development Fund under the Competitiveness Operational Program 2014-2020, titled "Physico-chemical analysis, nanostructured materials and devices for applications in the pharmaceutical field and medical in Romania", financing contract no. 58/05.09.2016 signed by the National Institute of Materials Physics with National Authority for Scientific Research and Innovation as an Intermediate Body on behalf of the Ministry of European Funds as Managing Authority for Operational Program Competitiveness (POC), subcontract D type, no. 2626/04.12.2017, signed by the National Institute of Materials Physics with Bioelectronics SRL.

Data Availability Statement: Samples of ASA and ASE are available from the authors.

Conflicts of Interest: The authors declare no conflict of interest. The funders had no role in the design of the study; in the collection, analyses, or interpretation of data; in the writing of the manuscript; or in the decision to publish the results.

\section{References}

1. Parolini, M. Toxicity of the Non-Steroidal Anti-Inflammatory Drugs (NSAIDs) acetylsalicylic acid, paracetamol, diclofenac, ibuprofen and naproxen towards freshwater invertebrates: A review. Sci. Total Environ. 2020, 740, 140043. [CrossRef] [PubMed]

2. Fokunang, C.N.; Fokunang, E.T.; Frederick, K.; Ngameni, B.; Ngadjui, B. Overview of non-steroidal anti-inflammatory drugs (nsaids) in resource limited countries. MOJ Toxicol. 2018, 4, 5-13. [CrossRef]

3. Bianconi, V.; Violi, F.; Fallarino, F.; Pignatelli, P.; Sahebkar, A.; Pirro, M. Is Acetylsalicylic Acid a Safe and Potentially Useful Choice for Adult Patients with COVID-19? Drugs 2020, 80, 1383-1396. [CrossRef] [PubMed]

4. Osbone, T.F.; Veigulis, Z.P.; Arreola, D.M.; Mahajan, S.M.; Roosli, E.; Curtin, C.M. Association of mortality and aspirin prescription for COVID-19 patients at the veterans health administration. PLoS ONE 2021, 16, e0246825.

5. Tsai, S.C.; Lu, C.C.; Bau, D.T.; Chiu, Y.J.; Yen, Y.T.; Hsu, Y.M.; Fu, C.W.; Kuo, S.C.; Lo, Y.S.; Chiu, H.Y.; et al. Approaches towards fighting the COVID-19 pandemic (review). Int. J. Molec. Med. 2021, 47, 3-22. [CrossRef] [PubMed]

6. Morris, G.; Bortolasci, C.G.; Puri, B.K.; Olive, L.; Marx, W.; O’Neil, A.; Athan, E.; Carvalho, A.; Maes, M.; Walder, K.; et al. Preventing the development of severe COVID-19 by modifying immunothrombosis. Life Sci. 2021, 264, 118617. [CrossRef] [PubMed]

7. Liao, D.; Zhong, L.; Duan, T.; Zhang, R.H.; Wang, X.; Wang, G.; Hu, K.; Lv, X.; Kang, T. Asprin suppresses the growth and metastasis of osteosarcoma through the NF-kB pathway. Clin. Cancer Res. Off. J. Am. Assoc. Cancer Res. 2015, 21, 5349-5359. [CrossRef]

8. Ornelas, A.; Zacharias-Millward, N.; Menter, D.G.; Davis, J.S.; Lichtenberger, L.; Hawke, D.; Hawk, E.; Vilar, E.; Bhattacharya, P.; Millward, S. Beyond COX-1: The effects of aspirin on platelet biology and potential mechanisms of chemoprevention. Cancer Metastasis Rev. 2017, 36, 289-303. [CrossRef] [PubMed]

9. Alfonso, L.; Ai, G.; Spittle, R.C.; Bhat, G.J. Molecular targets of aspirin and cancer prevention. Brit. J. Cancer 2014, 111, 61-67. [CrossRef]

10. Verardi, L.; De Lorenzis, E.; Natalello, G. Tolerability and safety of acetylsalicylic acid in patients with systemic sclerosis. Ann. Rheum. Dis. 2020, 79, 1606. [CrossRef]

11. Loomans-Kropp, H.A.; Pinsky, P.; Cao, Y.; Chan, A.T.; Umar, A. Association of Aspirin Use With Mortality Risk Among Older Adult Participants in the Prostate, Lung, Colorectal and Ovarian Cancer Screening Trial. JAMA Netw. Open 2019, 2, 1916729. [CrossRef] [PubMed]

12. Farias, S.; Boateng, J.S. In vitro, ex vivo and in vivo evaluation of taste masked low dose acetylsalicylic acid loaded composite wafers as platforms for buccal administration in geriatric patients with dysphagia. Int. J. Pharm. 2020, 589, 119807. [CrossRef] [PubMed]

13. Bugiardini, R.; Pavasović, S.; Yoon, J.; van der Schaar, M.; Kedev, S.; Vavlukis, M.; Badimon, L. Aspirin for primary prevention of ST segment elevation myocardial infarction in persons with diabetes and multiple risk factors. E-Clin. Med. 2020, $27,100548$.

14. Wang, Z.; Tang, Z.; Peng, X.; Zhu, W.; Ying-jia, X.; Ge, L.; Ge, J. Network Meta-analysis: Aspirin plus Traditional Chinese Medicine for stroke prevention in Patients with Atrial Fibrillation. J. Herb. Med. 2020, 22, 100355. [CrossRef]

15. Wang, S.; Yu, Y.; Ryan, P.M.; Dang, M.; Clark, C.; Kontogiannis, V.; Rahmani, J.; Varkaneh, H.K.; Salehisahlabadi, A.; Day, A.S.; et al. Association of aspirin therapy with risk of hepatocellular carcinoma: A systematic review and dose-response analysis of cohort studies with 2.5 million participants. Pharmacol. Res. 2020, 151, 104585. [CrossRef]

16. Dos Santos, F.D.A.G.; Leite-Andrade, M.C.; de Sousa Brandão, I.; da Silva Alves, A.I.; Buonafina, M.D.S.; Nunes, M.; de AraújoNeto, L.N.; de Freitas, M.A.; Brayner, F.A.; Alves, L.C.; et al. Anti-biofilm effect by the combined action of fluconazole and acetylsalicylic acid against species of Candida parapsilosis complex. Infect. Genet. Evol. 2020, 84, 104378. [CrossRef] 
17. Azboy, I.; Groff, H.; Goswami, K.; Vahedian, M.; Parvizi, J. Low-Dose Aspirin Is Adequate for Venous Thromboembolism Prevention Following Total Joint Arthroplasty: A Systematic Review. J. Arthroplasty 2020, 35, 886-892. [CrossRef] [PubMed]

18. Liu, H.; Xiong, C.; Liu, J.; Sun, T.; Ren, Z.; Li, Y.; Geng, J.; Li, X. Aspirin exerts anti-tumor effect through inhibiting Blimp1 and activating ATF4/CHOP pathway in multiple myeloma. Biomed. Pharm. 2020, 125, 110005. [CrossRef] [PubMed]

19. Acharya, S.; Daniel, A.; Gyadangi, B.; Ramsamy, S. Isolation, Characterization of a Potential Degradation Product of Aspirin and an HPLC Method for Quantitative Estimation of Its Impurities. J. Chromatogr. Sci. 2015, 53, 1491-1497. [CrossRef] [PubMed]

20. Khan, H.; Ali, M.; Ahuja, A.; Ali, J. Stability Testing of Pharmaceutical Products—Comparison of Stability Testing Guidelines. Curr. Pharm. Anal. 2010, 6, 142-150. [CrossRef]

21. Singh, R.; Tiwari, M.K.; Gangopadhayay, D.; Mishra, P.C.; Mishra, H.; Srivastava, A.; Singh, R.K. Detection and monitoring of in vitro formation of salicylic acid from aspirin using fluorescence spectroscopic technique and DFT calculations. J. Photoch. Photobiolgy B 2018, 189, 292-297. [CrossRef] [PubMed]

22. Wang, Y.; Xu, P.P.; Li, X.X.; Nie, K.; Tuo, M.-F.; Kong, B.; Chen, J. Monitoring the hydrolyzation of aspirin during the dissolution testing for aspirin delayed-release tablets with a fiber-optic dissolution system. J. Pharm. Anal. 2012, 2, 386-389. [CrossRef] [PubMed]

23. Husain, M.A.; Rehman, S.U.; Ishqi, H.M.; Sarwar, T.; Tabish, M. Spectroscopic and molecular docking evidence of aspirin and diflunisal binding to DNA: A comparative study. RSC Adv. 2015, 5, 64335-64345. [CrossRef]

24. Muthuselvi, C.; Dhavachitra, M.; Pandiarajan, S. Growth and Characterization of Aspirin Crystal in the Phosphoric acid Medium. J. Chem. Pharm. Res. 2016, 8, 804-814.

25. Zhen, X.-E.; Zong, M.; Gao, S.-N.; Cao, Y.-G.; Jiang, L.; Chen, S.-X.; Li, S. Preparation and Characterization of a Novel Aspirin Derivative with Anti-Thrombotic and Gastric Mucosal Protection Properties. PLoS ONE 2014, 9, e98513.

26. Motan, G.; Puia, A. Studies of different types of aspirin by spectrophotometric methods. Acta Chem. Iasi 2014, 22, 155-164. [CrossRef]

27. Szostak, R.; Mazurek, S. Quantitative determination of acetylsalicylic acid and acetaminophen in tablets by FT-Raman spectroscopy Electronic Supplementary Information available. Analyst 2001, 127, 144-148. [CrossRef] [PubMed]

28. Heng, J.Y.Y.; Bismarck, A.; Lee, A.F.; Wilson, K.; Williams, D.R. Anisotropic Surface Chemistry of Aspirin Crystals. J. Pharm. Sci. 2007, 96, 2134-2144. [CrossRef] [PubMed]

29. Ignaczak, A.; Porwański, S.; Szyszka, M. Deeper insight into the properties of the newly synthesized macrocycles as drug receptors - some preliminary quantum chemical studies. New J. Chem. 2017, 41, 521-529. [CrossRef]

30. De Aguiar, J.L.N.; Leandro, K.C.; Abrantes, S.D.M.P.; Albert, A.L.M. Development of a new analytical method for determination of acetylsalicylic and salicylic acids in tablets by reversed phase liquid chromatography. Braz. J. Pharm. Sci. 2009, 45, 723-727. [CrossRef]

31. Ramjith, S.; Sunith, D.K.; Radhakrishnan, S.; Sameer, P.A. HPLC study of aspirin and aspirin derivatives. Int. J. Res. Pharm. Chem. 2013, 3, 1-5.

32. Cofan, C.; Radovan, C. Anodic Determination of Acetylsalicylic Acid at a Mildly Oxidized Boron-Doped Diamond Electrode in Sodium Sulphate Medium. Int. J. Electrochem. 2011, 2011, 1-9. [CrossRef]

33. Mukherjee, D.; Ray, A.; Barghi, S. Mechanism of Acetyl Salicylic Acid (Aspirin) Degradation under Solar Light in Presence of a $\mathrm{TiO}_{2}$-Polymeric Film Photocatalyst. Processes 2016, 4, 13. [CrossRef]

34. Dai, Q.; Xia, Y.; Jiang, L.; Li, W.; Wang, J.; Chen, J. Enhanced Degradation of Aspirin by Electrochemical oxidation with Modified PbO2Electrode and Hydrogen Peroxide. Int. J. Electrochem. Sci. 2012, 7, 12895-12906.

35. Daescu, M.; Matea, A.; Negrila, C.; Serbschi, C.; Ion, A.C.; Baibarac, M. Photoluminescence as a valuable tool in the optical characterization of acetaminophen and the monitoring of its photodegradation reactions. Molecules 2020, 25, 4571. [CrossRef]

36. Daescu, M.; Toulbe, N.; Baibarac, M.; Mogos, A.; Lorinczi, A.; Logofatu, C. Photoluminescence as a complementary tool for UV-VIS spectroscopy to highlight the photodegradation of drugs: A case study on melatonin. Molecules 2020, 25, 3820. [CrossRef] [PubMed]

37. Baibarac, M.; Smaranda, I.; Nila, A.; Serbschi, C. Optical properties of folic acid in phosphate buffer solutions: The influence of pH and UV irradiation on the UV-VIS absorption spectra and photoluminescence. Sci. Rep. 2019, 9, 14278. [CrossRef] [PubMed]

38. Smaranda, I.; Nila, A.; Manta, C.M.; Samohvalov, D.; Gherca, D.; Baibarac, M. The influence of UV light on the azathioprine photodegradation: New evidences by photoluminescence. Results Phys. 2019, 14, 102443. [CrossRef]

39. Thiessen, J.J. Aspirin: Plasma concentration and effects. Thromb. Res. 1983, 29 (Suppl. IV), 105-111. [CrossRef]

40. Edwards, I.J. The hydrolysis of aspirin, Part 2. Trans. Faraday Soc. 1952, 48, 696-699. [CrossRef]

41. Kozma, L.; Hornak, I.; Eroshtak, I.; Nemet, B. Study of the fluorescent properties of salicylic acid derivates on solutions. Transl. Zheermal Prikl. Specktroscopii 1990, 53, 259-269.

42. Dumitrescu, V.; Surmeian, M.; Doneanu, C.; Stanescu, S. Computer program for the determination of salicylic acid content in aspirin by derivative spectrometry. Anal. Chim. Acta 1996, 333, 181-186. [CrossRef]

43. Premkumar, R.; Premkumar, S.; Rekha, T.N.; Parameswari, A.; Mathavan, T.; Benial, A.M.F. Surface enhanced Raman spectroscopic studies on aspirin: An experimental and theoretical approach. AIP Conf. Proc. 2016, 1728, 020613. 
44. Binev, I.G.; Stamboliyska, B.A.; Binev, Y.I. The infrared spectra and structure of acetylsalicylic acid (aspirin) and its oxyanion: An ab initio force field treatment. J. Molec. Struct. 1996, 378, 189-197.

45. Balci, A.K.; Koksal, O.; Kose, A.; Armagan, E.; Ozdemir, F.; Inal, T.; Oner, N. General characteristics of patients with electrolyte imbalance admitted to emergency department. World J. Emerg. Med. 2013, 4, 113-116. [CrossRef] [PubMed] 